Utah State University

DigitalCommons@USU

\title{
The Effect of Experience and Quantity-Based Pricing on the Valuation of a Curbside Recycling Program
}

Arthur J. Caplan

Utah State University

Therese Grijalva

Alok K. Bohara

Follow this and additional works at: https://digitalcommons.usu.edu/eri

\section{Recommended Citation}

Caplan, Arthur J.; Grijalva, Therese; and Bohara, Alok K., "The Effect of Experience and Quantity-Based Pricing on the Valuation of a Curbside Recycling Program" (2004). Economic Research Institute Study Papers. Paper 289.

https://digitalcommons.usu.edu/eri/289

This Article is brought to you for free and open access by the Economics and Finance at DigitalCommons@USU. It has been accepted for inclusion in Economic Research Institute Study Papers by an authorized administrator of DigitalCommons@USU. For more information, please contact digitalcommons@usu.edu.

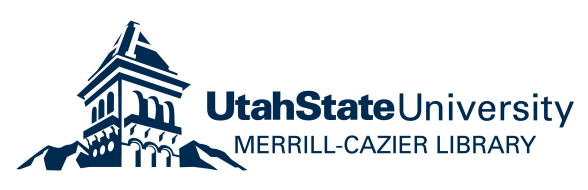


Economic Research Institute Study Paper

ERI \#2004-15

THE EFFECT OF EXPERIENCE AND QUANTITY-BASED PRICING ON THE VALUATION OF A CURBSIDE RECYCLING PROGRAM

by

ARTHUR J. CAPLAN

Department of Economics

Utah State University

3530 Old Main Hill

Logan, UT 84322-3530

THERESE GRIJALVA

Department of Economics

Weber State University

3807 University Circle

Ogden, UT 84408-3807

ALOK K. BOHARA

Department of Economics

University of New Mexico

Albuquerque, NM 87131

October 2004 


\title{
THE EFFECT OF EXPERIENCE AND QUANTITY-BASED PRICING ON THE VALUATION OF A CURBSIDE RECYCLING PROGRAM
}

\author{
Arthur J. Caplan, Assistant Professor \\ Department of Economics \\ Utah State University \\ 3530 Old Main Hill \\ Logan, UT 84322-3530 \\ Therese Grijalva, Assistant Professor \\ Department of Economics \\ Weber State University \\ 3807 University Circle \\ Ogden, UT 84408-3807 \\ Alok K. Bohara < Professor \\ Department of Economics \\ University of New Mexico \\ Albuquerque, NM 87131
}

The analyses and views reported in this paper are those of the author(s). They are not necessarily endorsed by the Department of Economics or by Utah State University.

Utah State University is committed to the policy that all persons shall have equal access to its programs and employment without regard to race, color, creed, religion, national origin, sex, age, marital status, disability, public assistance status, veteran status, or sexual orientation.

Information on other titles in this series may be obtained from: Department of Economics, Utah State University, 3530 Old Main Hill, Logan, UT 84322-3530.

Copyright (C) 2004 by Arthur J. Caplan, Therese Grijalva, and Alok K. Bohara. All rights reserved. Readers may make verbatim copies of this document for noncommercial purposes by any means, provided that this copyright notice appears on all such copies. 


\title{
THE EFFECT OF EXPERIENCE AND QUANTITY-BASED PRICING ON THE VALUATION OF A CURBSIDE RECYCLING PROGRAM
}

\author{
Arthur J. Caplan, Therese Grijalva, and Alok K. Bohara
}

\begin{abstract}
Quantity-based pricing for garbage collection services and recycling programs are becoming increasingly popular methods of meeting municipal solid waste diversion objectives. This article investigates household willingness to pay (WTP) for a pilot curbside recycling program $(\mathrm{CRP})$ in the presence of a quantity-based pricing scheme for garbage collection services. The pilot CRP provides a unique treatment effect that more precisely determines a household's level of real experience with curbside recycling than may be accomplished by respondents simply stating their experience levels. Moreover, unlike previous studies that have modeled the simultaneity of these household decisions as a two-step process, we jointly estimate the household's intentions using a full-information maximum-likelihood (FIML) approach. We find that participants in the pilot CRP are more likely than non-participants to reduce their container size and that for those that intend to reduce their container size, WTP for participants is larger than for non-participants. Taken together, these results suggest that the benefits of curbside recycling may be closely linked with the availability of a quantity-based pricing scheme for garbage collection. In particular, there appears to be a virtuous cycle for the household between choosing to recycle and reducing the size of its garbage container.

JEL Classification: C35, D12
\end{abstract}




\section{THE EFFECT OF EXPERIENCE AND QUANTITY-BASED PRICING ON THE VALUATION OF A CURBSIDE RECYCLING PROGRAM ${ }^{1}$}

\section{Introduction}

Throughout the U.S., diversion of municipal solid waste from landfills is a recurring public policy objective (USEPA, 1994; Goldstein and Madtes, 2000). Quantity-based pricing for garbage collection services and recycling programs are becoming increasingly popular methods of meeting this waste diversion objective (Ibid). In order for local policy makers to make informed decisions about whether to initiate a curbside recycling program (CRP), they need reliable estimates of willingness to pay (WTP) as well as information on how quantity-based pricing for non-recyclable material will affect a household's recycling behavior. Municipalities have the added pressure of uncovering any potential hurdles that may impede the provision of a $\mathrm{CRP}$, or they run the risk of program failure. As we show in this paper, piloting new programs followed by household surveys can effectively inform the decision-making process at the municipal level. The main advantage of basing the decision-making process on the outcome of a pilot program is that precise controls are available for household experience with the program. With this in mind, the overriding objective of this study is to examine the effects of experience (i.e. participation in a piloted CRP) and exposure to quantity-based pricing on household waste behavior and WTP for curbside recycling services.

We address this objective by exploring the provision of a pilot CRP in Logan, Utah.

\footnotetext{
${ }^{1}$ The authors express gratitude to Issa Hamud, Director, Division of Environmental Services, Logan, Utah, for implementing the pilot curbside recycling program and facilitating our efforts to complete a city-wide household survey. We also thank Jill Galloway of the Cache Valley Clean Team for coordinating the data collection and compilation phases of the project, and the many students who went door-to-door to complete the survey. Order of authorship is unassigned.
} 
Logan is similar to many other small cities across the country. It is growing quickly and bumping up against some of its physical constraints. One of these constraints is solid waste disposal. The city's 85-acre landfill-which also services the 19 other cities located in the county - is projected to reach capacity within the next 15 years. The 'usual suspects' lie behind the county's dwindling landfill capacity — a high population growth rate and an increase in the amount of per-capita solid waste generated.

In an effort to divert waste from the county landfill, Logan has implemented an ambitious drop-off recycling program and a modest quantity-based pricing scheme. The city is also experimenting with residential curbside recycling. Between the months of January and June of 2002, a CRP was piloted in two large neighborhoods with the twofold objective of assessing the program's potential impact on waste diversion rates and to obtain information on household WTP. This paper focuses on the latter objective.

At the conclusion of the six-month pilot period, an attempt was made to interview faceto-face each of the participating households (henceforth "participants") to obtain information on their recycling behavior (including whether they anticipated being able to switch to a smaller cart size for garbage collection as a result of having curbside recycling), and their WTP for the CRP. Similar face-to-face surveys were also conducted with households that were originally given the opportunity to participate in the pilot program but declined (henceforth "non-participants"), and households that are located in neighborhoods that were not targeted for the pilot program (henceforth "non-targeted"). All household subgroups valued a hypothetical CRP that was identical to the pilot program.

These three sub-groups - participants, non-participants, and non-targeted-provide a unique opportunity to examine the effects of respondent experience on the valuation of a CRP. 
In particular, we are able to test for the effect on WTP of a household having participated in an actual CRP (participants) rather than having been described an identical hypothetical CRP (nonparticipants and non-targeted). We are also able to control for unobserved factors that distinguish participants from those who did not agree to participate (non-participants). Our empirical results support the previous findings of Boyle et al. (1993) and Cameron and Englin (1997) that experience affects the mean WTP response. An important difference between these studies and ours, however, is that respondents in Boyle et al. and Cameron and Englin self-report their experience levels. In our study, respondent experience is determined precisely as the result of a treatment effect.

Similar to Berrens et al. (1998), a full-information maximum-likelihood (FIML) approach is used to model the simultaneity inherent in the choice that a household makes about garbage container size (for non-recyclable material) under quantity-based pricing and participation in curbside recycling. ${ }^{2}$ This approach accounts for the potential effects that cost savings through quantity-based pricing have on a household's WTP for curbside recycling. We find that participants in the pilot CRP are more likely than non-participants to reduce their container size and that among all households that intend to reduce their container size, WTP for participants is larger than for non-participants. Taken together, these results suggest that the benefits of curbside recycling may be closely linked with the availability of a quantity-based pricing scheme for garbage collection. In particular, there appears to be a virtuous cycle for the household between choosing to recycle and reducing the size of its garbage container.

\footnotetext{
${ }^{2}$ The focus of the Berrens et al. (1998) study was to jointly estimate the household's stated voting preference and WTP for instream-flow protection in New Mexico. Their overriding goal in using the fullinformation maximum-likelihood approach, as is ours with respect to choice of container size and WTP for curbside recycling, was to obtain reliable and consistent estimates of the household's behavioral intentions.
} 
The next section provides a brief background on Logan's waste management issues and the pilot CRP. Section 3 presents a simple theoretical model of household recycling behavior. Section 4 discusses the survey instrument designed for this study, describes the variables used in the econometric analysis, and provides descriptive statistics. Section 5 specifies the three main hypotheses we seek to test in this study and presents the empirical methods used to account for the simultaneity inherent in the household's intention to reduce its garbage container size and its WTP for curbside recycling. Section 6 provides results from various specifications of the empirical model and Section 7 concludes.

\section{Background on Waste Management Issues and the Pilot Curbside Recycling Program}

Cache County is Utah's northern-most county, abutting Idaho's southern border. Total population in the county is currently 91,400 , representing a growth of approximately 28 percent since 1990. Slightly under half of the population $(43,400)$ resides in Logan, the county's largest city (U.S Census Bureau, 2002). In 1996, the residents of Cache County generated approximately 4.91 pounds of solid waste per capita per day. This figure rose to 5.22 pounds in 1998 and was 5.04 pounds in 2001 (personal communication with the Logan City Environmental Services Division). By comparison, the national averages for 1990 and 2000 were both 4.5 pounds (USEPA, 2004).

In recent years, Logan has implemented several programs to reduce its solid waste stream, resulting in what it estimates to be a 30 -percent diversion rate. ${ }^{3}$ For example, to reduce its residential waste stream the city presently maintains 18 drop-off recycling sites that collect a

\footnotetext{
${ }^{3}$ This rate includes green waste and construction debris diverted from the landfill (personal communication with Issa Hamud, Director, Division of Environmental Services). The city does not report a separate diversion rate for recyclable materials at the household level.
} 
variety of materials (including green waste). The city also provides a modest volume-based pricing scheme for residential garbage collection, where households can choose between a 60gallon or 90-gallon container size. Average monthly household rates for the 60- and 90-gallon container sizes are $\$ 6.55$ and $\$ 11.65$, respectively. Households are charged an extra $\$ 1.85$ and \$3.60 per month, respectively, for each additional container (City of Logan, Utah, Environmental Services Division, 2002). By participating in the pilot program, households were therefore able to objectively assess their demand for garbage collection services (i.e. container size) with a CRP. Although the literature generally concurs that quantity-based, or "pay-as-you-throw" pricing induces households to increase their recycling rates (c.f., Van Houtven and Morris, 1999; Miranda et al., 1996), there are notable exceptions concerning the strength of this argument (c.f., Fullerton and Kinnaman, 1996; Reschovsky and Stone, 1994; and Hong and Adams, 1999).

Households that agreed to participate in the pilot program were each provided with one 90-gallon container to hold fibrous material (mixed paper and cardboard) and non-fibrous material (aluminum, tin, and plastic). According to a pre-arranged monthly schedule, the households set out their fibrous material one week and their non-fibrous material the next. Each household was therefore required to figure out for themselves how to store the material that was not scheduled to be collected at the end of that week. For example, if fibrous material was scheduled to be collected at the end of the week, the household filled the city-provided 90-gallon container with fibrous material during the week and stored its non-fibrous material in a container provided on its own. Once the fibrous material was collected, the household then transferred the non-fibrous material stored during that week into the 90 -gallon container and used its own container to store the fibrous material that accumulated during the coming week. The city's motive for structuring the collection process in this way was to reduce sorting costs on its end. 


\section{A Simple Theory of Household Recycling Behavior}

Household $i, \mathrm{i}=1, \ldots, \mathrm{n}$, is assumed to maximize utility by choosing recycling effort, $\mathrm{e}_{\mathrm{i}}$, and a composite good, $\mathrm{z}_{\mathrm{i}}$, subject to its budget constraint. Household solid waste, $\mathrm{w}_{\mathrm{i}}$, is generated as a function of consumption according to $\mathrm{w}_{\mathrm{i}}=\lambda \mathrm{z}_{\mathrm{i}}$, where $0<\lambda<1$, and curbside recycling effort transforms into recyclables according to the function $r_{i}=r\left(e_{i}\right)$ where $r(0)=0$. The function $r$ is assumed increasing and concave in $\mathrm{e}_{\mathrm{i}}{ }^{4}$ Preferences are given by,

$$
\mathrm{u}_{\mathrm{i}}=\mathrm{u}\left(\mathrm{z}_{\mathrm{i}}, l_{\mathrm{i}}, \mathrm{g}_{\mathrm{i}}, \mathrm{G} ; \theta_{\mathrm{i}}\right)
$$

where $l_{i}$ is the fraction of non-market time spent in leisure, $g_{i}=w_{i}-r_{i}$ is the net amount of landfill waste generated by the household, $\mathrm{G}=\Sigma_{\mathrm{i}} \mathrm{g}_{\mathrm{i}}$ is aggregate net waste generated in the community, and $\theta_{\mathrm{i}}$ is a vector of household-specific characteristics. There is a tradeoff between leisure and the effort required to clean, sort, store and deliver the recyclables (either to the curb or to a centralized drop-off site). We assume the tradeoff is given by $l_{\mathrm{i}}=1-\mathrm{e}_{\mathrm{i}}$, where maximum leisure is normalized to unity. We also assume that $u$ is strictly increasing in $\mathrm{z}_{\mathrm{i}}$ and $l_{\mathrm{i}}$, and weakly decreasing in $\mathrm{g}_{\mathrm{i}}$ and G. ${ }^{5}$ Similar to Andreoni's (1990) impure-altruism model, household $i$ may receive private non-pecuniary (e.g., "warm glow") benefits from recycling due to a sense of ethical fulfillment (measured at the margin by $-u_{\mathrm{g}}$ ), as well as public benefits associated with contributing to the community's aggregate level of recycling (e.g., helping to increase the landfill's lifespan), measured by $-\mathrm{u}_{\mathrm{G}}$. The existence of public benefits creates a possible external effect since households have no apparent incentive to fully internalize the effect of their private recycling activity on the welfare of other households.

The household budget constraint is represented by,

\footnotetext{
${ }^{4}$ Drop-off recycling involves an additional amount of effort, $\mathrm{c}_{\mathrm{i}}$, defined in terms of transportation costs. Therefore, drop-off-recycling effort will result in $r_{i}=r\left(e_{i}-c_{i}\right)$, where if $e_{i}<c_{i}$ then $r_{i}=0$.
} 


$$
\mathrm{I}_{\mathrm{i}}=\mathrm{pz} \mathrm{z}_{\mathrm{i}}+\mathrm{t}\left(\mathrm{r}_{\mathrm{i}}\right) \varphi_{\mathrm{i}}
$$

where $\mathrm{I}_{\mathrm{i}}$ is household income, $\mathrm{p}$ is $\mathrm{z}_{\mathrm{i}}^{\prime}$ 's corresponding price index, $\mathrm{t}$ is the recycling fee (net of any savings associated with quantity-based pricing, which is contingent upon the household's curbside recycling effort), and $\varphi_{\mathrm{i}}$ is a binary variable equal to one if household $i$ voluntarily signs up for the CRP and zero otherwise. ${ }^{6}$

In formulating its WTP for curbside recycling, the household first chooses its recycling effort to maximize (1) subject to (2) and the $\mathrm{r}\left(\mathrm{e}_{\mathrm{i}}\right)$ transformation function. The solution to this problem can then be used to derive the household's indirect utility function, $\mathrm{v}_{\mathrm{i}}=\mathrm{v}\left(\mathrm{p}, \mathrm{I}_{\mathrm{i}}, \theta_{\mathrm{i}}\right)$. Assuming $\mathrm{v}$ is strictly increasing in $\mathrm{I}_{\mathrm{i}}$, one can invert any reference $\mathrm{v}_{\mathrm{i}}$ with respect to $\mathrm{I}_{\mathrm{i}}$ to produce the household's expenditure function, $\mathrm{m}_{\mathrm{i}}=\mathrm{m}\left(\theta_{\mathrm{i}}, \mathrm{v}_{\mathrm{i}}\right)$, where $\mathrm{p}$ is dropped for convenience. In this case, we set the reference indirect utility, $\mathrm{v}_{\mathrm{i}}^{0}$, equal to the maximum utility for a household that does not participate in a CRP (either because it chooses not to, or a CRP does not exist). WTP for curbside recycling is then derived by subtracting the household's minimum expenditure given that it participates in the CRP from its minimum expenditure given that it does not participate,

$$
\mathrm{WTP}_{\mathrm{i}}=\mathrm{m}\left(\theta_{\mathrm{i}}, \mathrm{v}_{\mathrm{i}}^{0} \mid \varphi_{\mathrm{i}}=0\right)-\mathrm{m}\left(\theta_{\mathrm{i}}, \mathrm{v}_{\mathrm{i}}^{0} \mid \varphi_{\mathrm{i}}=1\right) .
$$

In other words, WTP for household $i$ is defined by the amount of income the household would willingly forego so as to participate in a CRP and maintain the original utility level $v_{i}^{0}$. The household's WTP for curbside recycling may be negative if the disutility of foregone leisure is sufficiently large relative to the utility gained from recycling.

\footnotetext{
${ }^{5} \mathrm{We}$ further assume that conditions on $\mathrm{u}$ are such that sufficient second-order conditions for utility maximization hold, ensuring a well-defined solution.
} 
Given that the household has the option of reducing its container size in formulating its WTP for curbside recycling, our survey and empirical methods must capture the simultaneity that exists between the processes governing a household's WTP for curbside recycling and its decision of whether to reduce its container size in order to take advantage of quantity-based pricing. This simultaneity is represented implicitly through the endogeneity of $t$ in (2), which in turn influences $\mathrm{WTP}_{\mathrm{i}}$ in (3). The joint-estimation procedure used to account for this simultaneity is described in detail in Section 5 .

\section{Survey Design, Variables, and Data}

A representative sample of Logan residents were surveyed over a four-month period, June through September 2002, to obtain preferences and values for the piloted CRP. A total of 516 interviews were conducted by a team of Utah State University undergraduate students and Logan city employees. The survey team was managed by the coordinator of the Cache Valley Clean Team, a city-sponsored organization initiated in 1998 to advertise recycling and waste reduction efforts throughout the county, and trained in how to conduct the survey by the authors. By training the survey team themselves, the authors ensured that the elicitation of information from the respondents would not be biased in any conceivable way.

To get a representative sample of Logan residents, the team of interviewers surveyed participants, non-participants, and non-targeted residents. Of the 516 households interviewed, 147 were participants (33\%), 138 non-participants $(29 \%)$, and 173 non-targeted $(38 \%)$. The response rates for participants, non-participants, and non-targeted were $73.5 \%, 69 \%$, and $86.5 \%$, respectively. Extra questions were added to the participant's and non-participant's survey

\footnotetext{
${ }^{6}$ To keep the model simple, we abstract from the possibility that households save money through the sale of drop-off recyclables. We note, however, that this feature could be incorporated into the budget constraint in a straightforward manner.
} 
instruments. For example, the participant survey included questions to obtain opinions about the quality of the pilot program and the extent of participation in the program. The non-participant survey included questions directed toward understanding their decision not to participate.

The survey must be designed to capture information for modeling the simultaneity that exists between household's WTP for curbside recycling and its decision of whether to reduce its garbage container size (henceforth container size) in order to take advantage of quantity-based pricing. ${ }^{7}$ Each survey commenced with a series of questions about the household's awareness and use of drop-off recycling, followed by a series of contingent valuation (CV) questions to estimate WTP for curbside recycling and contingent behavior (CB) questions to determine whether a household would reduce its container size if curbside recycling were offered. For nonparticipants and non-targeted, the description of the hypothetical program preceding the $\mathrm{CV}$ questions read,

For the next few questions, please imagine that you COULD have a curbside recycling service that collects aluminum cans, cardboard (corrugated and noncorrugated), paper, plastics \#1 and \#2, tin cans, and steel on staggered weeks. During weeks 1 and 3 fibrous material_cardboard and paper-would be collected, while during weeks 2 and 4 non-fibrous material-aluminum, plastics, tin cans, and steel-would be collected. The city would provide you with one additional cart, which you would put the fibrous material in during weeks 1 and 3 , and the non-fibrous material in during weeks 2 and 4. Your household would pay a fee for the recycling service, in addition to your current monthly garbage collection fee.

Because previous research has shown that "cheap-talk" statements that include, for example, reminders about budget constraints can be effective in mitigating hypothetical bias, households within each sub-group were randomly selected to either receive a cheap talk statement before the $\mathrm{CV}$ questions or not (thus approximately half of the respondents received

\footnotetext{
${ }^{7}$ The survey instrument(s) are available upon request from the authors.
} 
cheap talk in each group) (Cummings and Taylor, 1999; List, 2001; and Aadland and Caplan, 2003 and 2004). The cheap talk statement read, ${ }^{8}$

As you prepare to answer the next few questions, please keep in mind the following three things. First, keep in mind your household budget. In a typical month, at what price would your household be able to afford curbside recycling? Second, keep in mind that there are alternatives to curbside recycling such as recycling drop-off centers and landfills. And third, keep in mind that in previous surveys we have found that the amounts that people say they are willing to pay for curbside recycling are sometimes different from the amounts that they would actually be willing to pay when curbside recycling became available in their community. For this reason, as I read the following curbside recycling fees, please imagine your household is actually paying them.

Following Cameron and James (1987), our CV question is set in the single-bounded, dichotomous-choice (SBDC) format to elicit a household's WTP for curbside recycling through a "yes"-or-"no" valuation question. The question is: "Would you be willing to pay $\$ \tau$ for the service?" The bid amount $\tau$ is chosen randomly from a set of pre-determined values. ${ }^{9}$ By randomizing the opening bid, the possible effects of "starting-point bias" are reduced (Cameron, 1988 and Alberini, 1995a and b). The SBDC format also enables the estimation of negative WTP values, which is consistent with previous household recycling surveys suggesting that some households apparently need to be paid to participate (Aadland and Caplan, 2003; Haab and McConnell, 1997; and Aadland and Caplan, 1999).

The CV question is followed up with a preference-certainty question and a query about whether the respondent would be willing to pay extra for the added convenience of not having to sort fibrous from non-fibrous recyclable material. The preference-certainty question asks the

\footnotetext{
${ }^{8}$ This script is more neutral than what has recently been proposed in the literature, and reflects the caution implied by Carson et al.'s (1996) convergent-validity results suggesting that responses to hypothetical WTP questions may in fact understate those provided through revealed preference.

${ }^{9}$ For this study, the bid values are randomized across $\$ 2, \$ 4$, and $\$ 6$. These bid values reflect the city's expected range of per-household average costs for curbside recycling (personal communication with Issa Hamud, Director, Division of Environmental Services).
} 
respondents how certain they are of their WTP responses on a scale from $0 \%$ to $100 \%$, with the former(latter) percent implying perfect uncertainty(certainty).

Before ending the survey with a series of demographic questions, respondents were queried about their households' current container size and whether they would select a smaller container size (or fewer containers) if curbside recycling were offered. Specifically, respondents were asked to consider a variety of container sizes ranging from 30 to 90 gallons, and select the size and quantity they would prefer. Answers to this question were used to create a binary variable equaling 1 if a respondent indicated that her household would reduce its container size if a CRP were offered. Approximately 62 percent of the sample indicated that they would reduce their container size.

Table 1 contains a listing of the variables used in our regression analysis. The variable names, descriptions, means and standard deviations are provided. Most of our control variables are typical demographics-MALE controls for gender, COLLEGE for educational attainment, HIGHINC for household income level, HOME for home ownership status, CHILDREN for household size and AGE for age of respondent.

\section{[INSERT TABLE 1 HERE]}

Additional control variables used in this study include CHEAP for whether a respondent received a cheap talk script prior to answering the series of WTP questions; NONPART and NONTARG for whether the household declined to participate in or was not targeted for the pilot CRP; FORETHIC and FORMONEY for the household's motivation for recycling; ENVORG for the household's membership status in an environmental organization; DROPOFF for the household's use of drop-off recycling; CONVEN for whether a household would pay for the added convenience of not having to separate fibrous from non-fibrous recyclable material; 
CANTREDUCE indicates that the household currently uses a 60-gallon container, the smallest size currently available, and PERFCERT for preference certainty. Finally, our dependent variables are (1) $\mathrm{Y}_{1}$, which is an indicator variable for the household's latent, true WTP for curbside recycling, and (2) $\mathrm{Y}_{2}$ (or REDUCE), which indicates whether the household intends to reduce its container size with the advent of curbside recycling.

While approximately $79 \%$ and $67 \%$ of the sample is ethically motivated to recycle and use drop-off recycling, respectively, only $8 \%$ belong to an environmental organization. Approximately $27 \%$ of the sample would pay extra for the convenience of not having to separate fibrous from non-fibrous recyclable material, and $86 \%$ are certain of their WTP responses. The sample is reasonably representative of the Logan population with respect to income, although it has slightly greater percentages of females (70\% sample vs. $52 \%$ census) and home ownership ( $78 \%$ sample vs. $44 \%$ census).

\section{Hypotheses and Empirical Methodology}

We use a joint model to test the following alternative hypotheses,

H1: A significant positive correlation exists between the household's intention to reduce its container size (i.e., REDUCE) and it's WTP for curbside recycling $(\rho>0)$, i.e., $W T P$ for curbside recycling is, on average, larger for households that intend to reduce their container size (i.e., REDUCE =1) than for households not intending to reduce (i.e., $R E D U C E=0$ ). ${ }^{10}$

H2: Participants in the pilot CRP are more likely than non-participants and nontargeted households to reduce their container size.

H3: WTP for curbside recycling among participants in the pilot CRP is statistically different than WTP for non-participants.

\footnotetext{
${ }^{10}$ Even more precisely, this hypothesis can be stated as, "For any given bid amount, a household that responds "yes" to REDUCE is more likely to answer "yes" to the bid amount, on average, than a household that responds "no" to REDUCE".
} 
H1 provides a convenient test of whether our full-information maximum-likelihood model is an appropriate choice for modeling the household's joint-decision process. In specific, we presume that this joint-decision process is governed by a positive relationship between the household's intention to reduce its container size and its WTP for curbside recycling. In effect, this hypothesis presumes that $\partial \mathrm{t} / \partial \mathrm{r}_{i}<0$ in (2) (i.e., the household is able to reduce its container size (and thus it's garbage bill) as a result recycling), which, all else equal, implies a larger $\mathrm{WTP}_{\mathrm{i}}$ in (3).

H2 and H3, respectively, provide tests of whether the pilot CRP helped influence the household's intention to reduce its container size (i.e., there is a potential "learning-by-doing" effect) and its valuation of curbside recycling (i.e., there is a potential "valuation-by-doing" effect). Along the lines of Boyle et al. (1993) and Cameron and Englin (1997), which show that mean WTP for a public good can be positively affected by the respondent's level of experience with the good, these hypotheses presume that experience with the pilot CRP positively impacts the participant's ability (and thus intention) to reduce his container size and to better recognize the value of curbside recycling.

Hong and Adams (1999) suggest that a household's WTP for curbside recycling and its choice of container size under a quantity-based pricing scheme are simultaneous decisions. To account for this simultaneity, the authors assume a two-stage process of waste generation and recycling effort. They find that the household responds to increases in garbage pricing by increasing its recycling effort. Following Berrens et al. (1998), we use the FIML approach to investigate these two decisions. The FIML approach enables us to account for the simultaneity inherent in the discrete choices a household makes concerning container size under quantitybased pricing and WTP for curbside recycling. 
The approach essentially combines the two separate models that explain the household's joint decision. A REDUCE model (which estimates the household's intention to reduce its container size) is treated as a selection mechanism which is jointly estimated with a WTP model. Letting $\mathrm{Y}_{1 \mathrm{i}}^{*}$ represent (latent) $\mathrm{WTP}_{\mathrm{i}}$ and $\mathbf{X}_{1 \mathrm{i}}$ represent $\boldsymbol{\theta}_{\mathrm{i}}$, equation (3) can be re-written for estimation purposes as,

$$
\mathrm{Y}_{1 \mathrm{i}}^{*}=\boldsymbol{\beta}_{1} \mathbf{X}_{1 \mathrm{i}}+\sigma_{1} \varepsilon_{1 \mathrm{i}}
$$

where a (non-latent) indicator variable $Y_{i 1}=1$ if $Y_{i 1}^{*}>\tau$ and $Y_{1 i}=0$ otherwise, $X_{1 i}$ is a vector of individual characteristics and survey treatment effects (e.g., CHEAP), $\beta_{1}$ is the (constant) coefficient row vector, $\sigma_{1}$ is the S.D., $\varepsilon_{1 \mathrm{i}}$ is a mean-zero error term, and $\tau$ is the randomized bid amount.

A selection, or REDUCE, equation is jointly estimated with (4) as,

$$
\mathrm{Y}_{2 \mathrm{i}}^{*}=\boldsymbol{\beta}_{2} \mathbf{X}_{2 \mathrm{i}}+\sigma_{2} \varepsilon_{2 \mathrm{i}}
$$

where $\mathrm{Y}_{2 \mathrm{i}}^{*}$ represents the household's (latent) intention to reduce its container size, $\mathbf{X}_{2 \mathrm{i}}$ is a vector of individual characteristics and survey treatment effects, $\beta_{2}$ is the corresponding coefficient row vector, $\sigma_{2}$ is the S.D. and $\varepsilon_{2 \mathrm{i}}$ is a mean-zero error term. Similar to the WTP equation, we employ a (non-latent) indicator variable $Y_{2 \mathrm{i}}=1$ if $\mathrm{Y}_{2 \mathrm{i}}^{*}>0$ and $\mathrm{Y}_{2 \mathrm{i}}=0$ otherwise.

We assume that the error terms for (4) and (5) are jointly normally distributed and, following Berrens et al. (1998), $\sigma_{2}$ is normalized to one. The joint likelihood function used to estimate equations (4) and (5) can be written as ( $i$ subscripts are dropped for convenience),

$$
\begin{aligned}
& \mathrm{L}\left(\boldsymbol{\beta}_{1}, \boldsymbol{\beta}_{2}, \rho\right) \\
& =\prod_{\mathrm{i}=1}^{\mathrm{n}}\left[\mathrm{P}\left(\mathrm{Y}_{1}^{*}>\tau, \mathrm{Y}_{2}^{*}>0\right)\right]^{\mathrm{Y}_{1} \mathrm{Y}_{2}} \times\left[\mathrm{P}\left(\mathrm{Y}_{2}^{*}>0\right)-\mathrm{P}\left(\mathrm{Y}_{1}^{*}>\tau, \mathrm{Y}_{2}^{*}>0\right)\right]^{\left(1-\mathrm{Y}_{1}\right) \mathrm{Y}_{2}} \\
& \times\left[\mathrm{P}\left(\mathrm{Y}_{1}^{*}>\tau\right)-\mathrm{P}\left(\mathrm{Y}_{1}^{*}>\tau, \mathrm{Y}_{2}^{*}>0\right)\right]^{\mathrm{Y}_{1}\left(1-\mathrm{Y}_{2}\right)} \times\left[\mathrm{P}\left(\mathrm{Y}_{1}^{*} \leq \tau, \mathrm{Y}_{2}^{*} \leq 0\right)\right]^{\left(1-\mathrm{Y}_{1}\right)\left(1-\mathrm{Y}_{2}\right)}
\end{aligned}
$$


Following Cameron and James (1987), $\mathrm{Y}_{1}^{*}$ is modeled directly from a dichotomouschoice CV question using a censored threshold approach. Accordingly, the set of four possible joint probabilities for the household's problem can be written as,

$$
\begin{aligned}
& \text { "yes" (to } \tau) \text { and "yes" (to REDUCE): } \\
& \mathrm{P}\left(\varepsilon_{1}>\left(\tau-\boldsymbol{\beta}_{1} \mathbf{X}_{1}\right) / \sigma_{1}, \varepsilon_{2}>-\boldsymbol{\beta}_{2} \mathbf{X}_{2} / \sigma_{2}\right) \\
& =1-\Phi\left[\frac{\tau-\boldsymbol{\beta}_{1} \mathbf{X}_{1}}{\sigma_{1}}\right]-\Phi\left[\frac{-\boldsymbol{\beta}_{2} \mathbf{X}_{2}}{\sigma_{2}}\right]+\Phi\left[\frac{\tau-\boldsymbol{\beta}_{1} \mathbf{X}_{1}}{\sigma_{1}}, \frac{-\boldsymbol{\beta}_{2} \mathbf{X}_{2}}{\sigma_{2}}, \rho\right]=\mathrm{A} \\
& \text { "no" (to } \tau) \text { and "yes" (to REDUCE): } \\
& \mathrm{P}\left(\varepsilon_{1}<\left(\tau-\boldsymbol{\beta}_{1} \mathbf{X}_{1}\right) / \sigma_{1}, \varepsilon_{2}>-\boldsymbol{\beta}_{2} \mathbf{X}_{2} / \sigma_{2}\right)=\left(1-\Phi\left[\frac{\tau-\boldsymbol{\beta}_{1} \mathbf{X}_{1}}{\sigma_{1}}\right]\right)-\mathrm{A} \\
& \text { "yes" (to } \tau) \text { and "no" (to REDUCE): } \\
& \mathrm{P}\left(\varepsilon_{1}>\left(\tau-\boldsymbol{\beta}_{1} \mathbf{X}_{1}\right) / \sigma_{1}, \varepsilon_{2}<-\boldsymbol{\beta}_{2} \mathbf{X}_{2} / \sigma_{2}\right)=\left(1-\Phi\left[\frac{-\boldsymbol{\beta}_{2} \mathbf{X}_{2}}{\sigma_{2}}\right]\right)-\mathrm{A} \\
& \text { "no" (to } \tau) \text { and "no" (to REDUCE): } \\
& \mathrm{P}\left(\varepsilon_{1}<\left(\tau-\boldsymbol{\beta}_{1} \mathbf{X}_{1}\right) / \sigma_{1}, \varepsilon_{2}<-\boldsymbol{\beta}_{2} \mathbf{X}_{2} / \sigma_{2}\right)=\Phi\left[\frac{\tau-\boldsymbol{\beta}_{1} \mathbf{X}_{1}}{\sigma_{1}}, \frac{-\boldsymbol{\beta}_{2} \mathbf{X}_{2}}{\sigma_{2}}, \rho\right]
\end{aligned}
$$

where $\Phi[\cdot]$ represents the joint cumulative distribution function (CDF) of the standardized normal random variates and $\rho$ is the correlation parameter defining the degree to which common elements in $\mathbf{X}_{1}$ and $\mathbf{X}_{2}$ explain the covariation in the REDUCE and WTP models.

To test H1, we begin by performing a likelihood ratio test, where a restricted version of equations (7) with $\rho=0$ is estimated. In addition, WTP for those who stated "yes" to REDUCE is estimated separately from those who stated "no." Following Berrens et al. (1998), the marginal mean WTP estimates for each of the sub-samples of households that stated "yes" and "no" to the REDUCE question are, respectively, 


$$
\begin{aligned}
& \text { E }[\text { WTP } \mid \text { REDUCE }=\text { "yes" }]=\Phi\left[\boldsymbol{\beta}_{2} \mathbf{X}_{2}\right]\left(\boldsymbol{\beta}_{1} \mathbf{X}_{1}+\rho \sigma_{1} \frac{\varphi\left[\boldsymbol{\beta}_{2} \mathbf{X}_{2}\right]}{\Phi\left[\boldsymbol{\beta}_{2} \mathbf{X}_{2}\right]}\right) \\
& \mathrm{E}\left[\text { WTP } \mid \text { REDUCE }=\text { "no"] }=\Phi\left[-\boldsymbol{\beta}_{2} \mathbf{X}_{2}\right]\left(\boldsymbol{\beta}_{1} \mathbf{X}_{1}-\rho \sigma_{1} \frac{\varphi\left[\boldsymbol{\beta}_{2} \mathbf{X}_{2}\right]}{\Phi\left[-\boldsymbol{\beta}_{2} \mathbf{X}_{2}\right]}\right)\right.
\end{aligned}
$$

where $\varphi$ is the standard-normal probability distribution function, $\Phi\left[\beta_{2} \mathbf{X}_{2}\right]$ represents the proportion of respondents who stated "yes" to the REDUCE question, and $\Phi\left[-\beta_{2} \mathbf{X}_{2}\right]$ is the proportion of respondents stating "no". The entire sample marginal mean is the sum of (8a) and (8b):

$$
\mathrm{E}[\mathrm{WTP}]=\Phi\left[\boldsymbol{\beta}_{2} \mathbf{X}_{2}\right]\left(\boldsymbol{\beta}_{1} \mathbf{X}_{1}+\rho \sigma_{1} \frac{\varphi\left[\boldsymbol{\beta}_{2} \mathbf{X}_{2}\right]}{\Phi\left[\boldsymbol{\beta}_{2} \mathbf{X}_{2}\right]}\right)+\Phi\left[-\boldsymbol{\beta}_{2} \mathbf{X}_{2}\right]\left(\boldsymbol{\beta}_{1} \mathbf{X}_{1}-\rho \sigma_{1} \frac{\varphi\left[\boldsymbol{\beta}_{2} \mathbf{X}_{2}\right]}{\Phi\left[-\boldsymbol{\beta}_{2} \mathbf{X}_{2}\right]}\right)
$$

A positive correlation $(\rho>0)$ therefore implies that a modeling approach which ignores the REDUCE intention will underestimate mean WTP for those who state "yes" to REDUCE and overestimate the mean WTP for those who state "no".

The test of $\mathbf{H 2}$ is based on the significance level of the appropriate coefficient estimate in $\beta_{2}$ (discussed further below), while the test of $\mathbf{H 3}$ is performed by directly comparing the WTP estimates across the two sub-samples of participants and non-participants (also discussed further below).

\section{Empirical Results}

The results for the joint REDUCE and WTP model (i.e., equations (4) and (5)) are presented in Table 2. Both unrestricted and restricted $(\rho=0)$ models are estimated. Summary statistics for each model are presented in the bottom section of the table. First, we perform an initial test of hypothesis H1 to determine whether the household's decision to reduce its container size and its WTP for curbside recycling are positively correlated. Using the results from the 
unrestricted model, the estimated value for $\rho(=0.28)$ is highly significant at the 0.01 level, suggesting that a positive correlation exists between the REDUCE and WTP decisions and that an endogenous selection process underlies the two decisions. Further, the likelihood ratio test for testing $\rho=0$ further confirms that the decisions are jointly related and that there is a gain in statistical efficiency in estimating the decisions jointly $\left(\chi^{2}=8.04\right.$ is greater than the critical value of 7.98 at the 0.01 level of significance). Therefore, we are able to reject the null hypothesis that $\rho=0$, and henceforth confine our attention to the unrestricted model.

\section{[INSERT TABLE 2 HERE]}

As the results in Table 2 demonstrate, several of the estimated coefficients for the joint REDUCE and WTP model conform to expectations. Beginning with the REDUCE model, the coefficients on COLLEGE, AGE, ENVORG, and FORMONEY are all significant and positively related to household's intention to reduce its container size. Conversely, an inverse relationship exists between REDUCE and both those who chose not to participate in the piloted CRP (NONPART) and homeowners $(\mathrm{HOME}=1)$. This partially confirms H2. ${ }^{11}$ By declining to participate in the pilot CRP, NONPART households likely signaled their lack of concern or interest in waste-management alternatives, and thus would also be less likely to reduce their container size. Lastly, and somewhat surprisingly, an inverse relationship also exists between REDUCE and CHEAP. As Aadland and Caplan (2004) point out, it is possible that by having "erred" on the side of conciseness, our short but balanced cheap-talk script provided respondents with insufficient detail, resulting in unpredictable effects on WTP.

\footnotetext{
${ }^{11}$ Recall that we also predicted that non-targeted households would also be less likely than participants to reduce their container size. Although the coefficient estimate on NONTARG is negative $(-0.15)$ it is statistically insignificant.
} 
By following the Cameron and James (1987) approach, the WTP coefficients are estimated directly. The scale parameter $\sigma_{1}$ is positive and highly significant indicating an inverse relationship between the bid amount, $\tau$, and acceptance of that bid amount. Similar to previous recycling studies, the estimated coefficients for the WTP equation indicate that WTP is positively related to HIGHINC, DROPOFF, and PERFCERT and negatively related to AGE and MALE. ${ }^{12}$ As mentioned in Section 5, hypotheses $\mathbf{H 1}$ and $\mathbf{H 3}$ can be tested using results from the unrestricted model and — in the case of H1 — using equations (8). Table 3 presents estimated WTP results with their respective $95 \%$ confidence intervals generated using the Delta Method Approximation (Greene, 2003).

\section{[INSERT TABLE 3 HERE]}

We begin by performing a (subsequent) test of hypothesis H1. As shown in Table 3, the marginal mean WTP estimates for the entire sample (of participants, non-participants, and nontargeted households) are $\$ 4.04$ for those who intend to reduce their container size and $\$ 1.85$ for those who do not, implying via (8c) a marginal mean WTP of $\$ 5.89$ for the entire sample. Using a standard means-difference approach, the WTP amount for those who stated "yes" to the reduce question, $\$ 4.04$, is statistically different than $\$ 1.85$ for those who stated "no" (t-value $=4.29$ ). This is additional evidence in support of $\mathbf{H 1}$.

In a similar vein, WTP for participants and non-targeted who answered "yes" to the REDUCE question is greater than the WTP for those who answered "no." However, a different result occurs for non-participants. Beginning with the participant sub-sample, the WTP amounts for those who answered "yes" and "no" to REDUCE are $\$ 5.17$ and $\$ 1.17$, respectively. This difference in WTP is statistically different at the $1 \%$ level of significance (with a t-value of 5.62). Similarly, for the non-targeted sub-sample the respective WTP amounts are $\$ 4.65$ (REDUCE $=$

\footnotetext{
${ }^{12}$ See for instance Aadland and Caplan (1999 and 2003), Caplan, et al. (2002), and Lake, et al. (1996).
} 
"yes") and \$1.15 (REDUCE = "no"), which is also statistically significant at the 1\% level (tvalue $=5.47)$. For the non-participant sub-sample, the WTP amounts for those who said "yes" and "no" to REDUCE are \$2.18 and \$3.36, respectively. While \$2.18 (REDUCE = "yes") is statistically different than $\$ 3.36$ (REDUCE $=$ "no") at the 0.05 level, the direction of the difference between these two WTP estimates is puzzling. Perhaps non-participants who stated "yes" to REDUCE believe that the added non-market costs of recycling will actually outweigh the savings in garbage costs due to a reduction in container size.

Lastly, we test hypothesis $\mathbf{H 3}$, that there is a statistical difference in WTP among the three sub-samples - participants, non-participants, and non-targeted. Using the marginal mean WTP amount for the entire sub-sample for each group, we are unable to accept $\mathbf{H 3}$ (i.e., that the WTP amounts for these three sub-groups are statistically different from one another). We cannot reject the null hypothesis that no statistical difference exists between \$6.34 (participants), \$5.54 (non-participants), and \$5.81 (non-targeted). However, we do find a statistical difference in WTP amounts for participants and non-participants according to their responses to the REDUCE question, i.e., \$5.17 (participant, REDUCE = “yes”) is statistically different than $\$ 2.18$ (nonparticipant, REDUCE $=$ "yes") at the 0.01 level of significance (t-value $=3.86)$. In addition, \$1.17 (participant, REDUCE = "no") is statistically different than \$3.36 (non-participant, REDUCE $=$ "no") at the 0.01 level of significance $(t-v a l u e=4.21)$. These results suggest that only those participants who were able to recognize a way to reduce their container sizes (perhaps as a result of participating in pilot CRP) stated a higher WTP for curbside recycling. Table 4 summarizes these results for $\mathbf{H 1}$ and $\mathbf{H} 3$.

[INSERT TABLE 4 HERE] 


\section{Conclusion}

The overriding objective of this study was to examine the effects of experience (i.e., participation in a piloted CRP) and exposure to quantity-based pricing on household waste behavior and WTP for curbside recycling services. To test the specific hypotheses underlying this objective, we have estimated an empirical model that accounts for the joint-decision process households follow in choosing whether to reduce their garbage container size and in formulating their WTP for curbside recycling. We have found that these two decisions are positively related.

In particular, we have found that participants in the pilot CRP are more likely than nonparticipants to reduce their container size and that among all households that intend to reduce their container size, WTP for participants is larger than for non-participants. Taken together, these results suggest that the benefits of curbside recycling may be closely linked with the availability of a quantity-based pricing scheme for garbage collection. In other words, households that choose to participate in curbside recycling and who are able to leverage that participation in reducing their garbage container size tend to have a larger WTP for recycling. Thus, there appears to be a virtuous cycle for the household between choosing to recycle and reducing the size of its garbage container.

\section{References}

Aadland, D. and A.J. Caplan. 2004. "Cheap Talk Reconsidered: New Evidence from CVM," Economic Research Institute Working Paper 2002-20, Utah State University.

Aadland, D. and A.J. Caplan. 1999. "Household Valuation of Curbside Recycling." Journal of Environmental Planning and Managemen, 42(6): 781-799.

Aadland, D. and A.J. Caplan. 2003. "Willingness to Pay for Curbside Recycling With Detection and Mitigation of Hypothetical Bias." American Journal of Agricultural Economics 85(2): 492-502. 
Alberini, A. 1995a. "Efficiency vs. Bias of Willingness-to-Pay Estimates: Bivariate and Interval Data Models.” Journal of Environmental Economics and Management 29: 169-180.

Alberini, A. 1995b. "Optimal Designs for Discrete Choice Contingent Valuation Surveys: Single-Bound, Double-Bound, and Bivariate Models.” Journal of Environmental Economics and Management, 28: 287-306.

Berrens, R.P., A.K. Bohara, H. Jenkins-Smith, C.L. Silva, P. Ganderton, and D. Brookshire. 1998. "A Joint Investigation of Public Support and Public Values: Case of Instream Flows in New Mexico.” Ecological Economics, 27: 189-203.

Boyle, K.J., M.P. Welsh, and R.C. Bishop. 1993. "The Role of Question Order and Respondent Experience in Contingent-Valuation Studies." Journal of Environmental Economics and Management 25: S-80-S-99.

Cameron, T.A. 1988. “A New Paradigm for Valuing Non-Market Goods Using Referendum Data: Maximum Likelihood Estimation by Censored Logistic Regression." Journal of Environmental Economics and Management, 15: 355-379.

Cameron, T.A. and J. Englin. 1997. "Respondent Experience and Contingent Valuation of Environmental Goods." Journal of Environmental Economics and Management 33: 296313.

Cameron, T.A. and M. D. James. 1987. "Efficient Estimation Methods for 'Close-Ended' Contingent Valuation Surveys." Review of Economics and Statistics 69: 269-276.

Caplan, A.J., T. Grijalva, and P.Jackus. 2002. "Waste Not or Want Not? A Contingent Ranking Analysis of Curbside Waste Disposal Options,” Ecological Economics 43: 185-197.

Carson, R.T., N.E. Flores, K. M. Martin, and J.L. Wright. 1996. “Contingent Valuation and Revealed Preference Methodologies: Comparing the Estimates for Quasi-Public Goods." Land Economics 72: 80-99.

City of Logan, Utah, Environmental Services Division. 2002. http://www.ci.logan.ut.us/envdiv/Collection/c_rates\&fees.htm. Retrieved 10/27/02.

Cummings, R.G. and L. O.Taylor. 1999. "Unbiased Value Estimates for Environmental Goods: A Cheap Talk Design for the Contingent Valuation Method.” American Economic Review 89(3): 649-666.

Fullerton, D. and T.C. Kinnaman. 1996. "Household Responses to Pricing Garbage by the Bag." American Economic Review 86(4): 971-984.

Goldstein, N., and C. Madtes. 2000. "The State of Garbage in America (Part 2)." Biocycle 41: 40-8. 
Greene, W.H. 2003. Econometric Analysis - Fifth Edition. Pearson Education, Inc., Singapore.

Haab, T.C. and K. E. McConnell. 1997. "Referendum Models and Negative Willingness to Pay: Alternative Solutions." Journal of Environmental Economics and Management 32: 251270.

Hong, S. and R.M. Adams. 1999. "Household Responses to Price Incentives for Recycling: Some Further Evidence.” Land Economics 75(4): 505-514.

Lake, I.R., I. J. Bateman, and J. P. Parfitt. 1996. "Assessing a Kerbside Recycling Scheme: A Quantitative and Willingness to Pay Case Study." Journal of Environmental Management 46: 239-254.

List, J.A. 2001. "Do Explicit Warnings Eliminate the Hypothetical Bias in Elicitation Procedures? Evidence from Field Auctions for Sportscards." American Economic Review 91(5): 1498-1507.

Miranda, M.L., S.D. Bauer, and J.E. Aldy. 1996. "Unit Pricing Programs for Residential Municipal Solid Waste: An Assessment of the Literature." U.S. EPA Cooperative Agreement \#CR822-927-010, Office of Policy, Planning and Evaluation, U.S. Environmental Protection Agency.

Reschovsky, J.D. and S.E. Stone. 1994. "Market Incentives to Encourage Household Waste Recycling: Paying for What You Throw Away." Journal of Policy Analysis and Management 13(1): 120-139.

U.S. Census Bureau. 2002. U.S. Census of Population 2000.

U.S. Environmental Protection Agency (USEPA). 2004. http://www.epa.gov/epaoswer/nonhw/muncpl/facts.htm.

Van Houtven, G. L. and G.E. Morris. 1999. "Household Behavior Under Alternative Pay-AsYou-Throw Systems for Solid Waste Disposal." Land Economics November 1999, 75(4): 515-537. 
Table 1. Variable Names, Descriptions, and Descriptive Statistics

\begin{tabular}{|c|c|c|c|}
\hline Variables & Description & Mean & $\begin{array}{l}\text { Standard } \\
\text { Deviation }\end{array}$ \\
\hline \multicolumn{4}{|l|}{ Dependent Variables } \\
\hline $\mathrm{Y}_{1}(\mathrm{WTP})$ & $\begin{array}{l}\text { Willing to pay specified bid amount, } \tau \text {, for a CRP }(1= \\
\text { "yes", } 0=\text { "no") }\end{array}$ & 0.64 & 0.48 \\
\hline $\mathrm{Y}_{2}(\mathrm{REDUCE})$ & $\begin{array}{l}\text { Will likely reduce garbage container size if a CRP were } \\
\text { made available ( } 1=\text { "yes", } 0=\text { "no") }\end{array}$ & 0.60 & 0.49 \\
\hline \multicolumn{4}{|l|}{ Independ. Variables } \\
\hline MALE & $\begin{array}{l}\text { Dummy Variable }-1 \text { indicates that the respondent is } \\
\text { male, } 0 \text { otherwise }\end{array}$ & 0.30 & 0.46 \\
\hline COLLEGE & $\begin{array}{l}\text { Dummy Variable }-1 \text { indicates that the respondent has } \\
\text { completed some college, } 0 \text { otherwise. }\end{array}$ & 0.61 & 0.49 \\
\hline HIGHINC & $\begin{array}{l}\text { Dummy Variable }-1 \text { indicates that the household's } \\
\text { annual income is above } \$ 50,000,0 \text { otherwise. }\end{array}$ & 0.38 & 0.49 \\
\hline CHEAP & $\begin{array}{l}\text { Dummy Variable }-1 \text { indicates that the respondent } \\
\text { received cheap talk statement, } 0 \text { otherwise. }\end{array}$ & 0.50 & 0.50 \\
\hline NONPART & $\begin{array}{l}\text { Dummy Variable }-1 \text { indicates that the household elected } \\
\text { not to participate in the pilot recycling program, } 0 \\
\text { otherwise. }\end{array}$ & 0.31 & 0.46 \\
\hline NONTARG & $\begin{array}{l}\text { Dummy Variable }-1 \text { indicates that the household was } \\
\text { not offered a chance to participate in the pilot recycling } \\
\text { program, } 0 \text { otherwise. }\end{array}$ & 0.37 & 0.48 \\
\hline HOME & $\begin{array}{l}\text { Dummy Variable }-1 \text { indicates that the household is } \\
\text { homeowner, } 0 \text { otherwise. }\end{array}$ & 0.78 & 0.41 \\
\hline CHILDREN & $\begin{array}{l}\text { Dummy Variable }-1 \text { indicates that the household has } \\
\text { resident children under the age of } 18,0 \text { otherwise. }\end{array}$ & 0.23 & 0.42 \\
\hline AGE & Respondent's age in years (scaled by a factor of 10 ). & 4.31 & 1.62 \\
\hline ENVORG & $\begin{array}{l}\text { Dummy Variable }-1 \text { indicates that the household is a } \\
\text { member of an environmental organization, } 0 \text { otherwise. }\end{array}$ & 0.08 & 0.28 \\
\hline CONVEN & $\begin{array}{l}\text { Dummy Variable }-1 \text { indicates that the household would } \\
\text { be willing to pay more for added convenience of not } \\
\text { having to separate fibrous from non-fibrous material, } 0 \\
\text { otherwise. }\end{array}$ & 0.27 & 0.45 \\
\hline DROPOFF & $\begin{array}{l}\text { Dummy Variable }-1 \text { indicates that the household has } \\
\text { used drop-off recycling during the past } 12 \text { months, } 0 \\
\text { otherwise. }\end{array}$ & 0.67 & 0.47 \\
\hline FORETHIC & $\begin{array}{l}\text { Dummy Variable }-1 \text { indicates that the household } \\
\text { recycles for ethical reasons, } 0 \text { otherwise. }\end{array}$ & 0.79 & 0.41 \\
\hline PREFCERT & Percent certain of response to randomized bid amount. & 0.86 & 0.27 \\
\hline FORMONEY & $\begin{array}{l}\text { Dummy Variable }-1 \text { indicates that the household } \\
\text { recycles to save money, } 0 \text { otherwise. }\end{array}$ & 0.36 & 0.48 \\
\hline CANTREDUCE & $\begin{array}{l}\text { Dummy Variable }-1 \text { indicates that household has a } 60 \text { - } \\
\text { gallon garbage container (the smallest size currently } \\
\text { available), and therefore does not currently have an } \\
\text { option to reduce to a smaller size, } 0 \text { otherwise. }\end{array}$ & 0.10 & 0.31 \\
\hline
\end{tabular}


Table 2. Model Estimation Results $(n=395)$

\begin{tabular}{|c|c|c|c|c|}
\hline \multirow[t]{2}{*}{ Variables } & \multicolumn{2}{|c|}{ Unrestricted Model } & \multicolumn{2}{|c|}{ Restricted Model } \\
\hline & WTP & REDUCE & WTP & REDUCE \\
\hline \multirow[t]{2}{*}{ INTERCEPT } & $\overline{2.27}$ & $0.72 * *$ & $\overline{1.63}$ & $0.69 * *$ \\
\hline & (1.13) & $(2.36)$ & $(0.84)$ & $(2.25)$ \\
\hline \multirow{2}{*}{ MALE } & $-2.40 * * *$ & 0.02 & $-2.20 * * *$ & 0.02 \\
\hline & $(-2.81)$ & $(0.11)$ & $(-2.75)$ & $(0.14)$ \\
\hline \multirow[t]{2}{*}{ COLLEGE } & 0.86 & $0.35 * *$ & 0.78 & $0.35^{* *}$ \\
\hline & (1.13) & $(2.21)$ & $(1.07)$ & $(2.21)$ \\
\hline \multirow[t]{2}{*}{ HIGHINC } & $1.68 * *$ & -0.25 & $1.54^{*}$ & -0.24 \\
\hline & $(2.01)$ & $(-1.55)$ & $(1.92)$ & $(-1.50)$ \\
\hline \multirow[t]{2}{*}{ CHEAP } & -0.74 & $-0.27^{*}$ & -0.74 & $-0.26^{*}$ \\
\hline & $(-1.07)$ & $(-1.88)$ & $(-1.12)$ & $(-1.85)$ \\
\hline \multirow{2}{*}{ NONPART } & -0.46 & $-1.01 * * *$ & -0.28 & $-1.01 * * *$ \\
\hline & $(-0.51)$ & $(-5.34)$ & $(-0.32)$ & $(-5.32)$ \\
\hline \multirow[t]{2}{*}{ NONTARG } & 0.03 & -0.15 & -0.02 & -0.14 \\
\hline & $(0.04)$ & $(-0.83)$ & $(-0.03)$ & $(-0.81)$ \\
\hline \multirow{2}{*}{ HOME } & -0.15 & $-0.81 * * *$ & 0.09 & $-0.80 * * *$ \\
\hline & $(-0.15)$ & $(-3.71)$ & $(0.09)$ & $(-3.68)$ \\
\hline \multirow[t]{2}{*}{ CHILDREN } & -0.62 & 0.27 & -0.64 & 0.27 \\
\hline & $(-0.70)$ & (1.48) & $(-0.75)$ & (1.48) \\
\hline \multirow{2}{*}{ AGE } & $-1.18 * * *$ & $0.09 *$ & $-1.17 * * *$ & $0.09 *$ \\
\hline & $(-3.48)$ & $(1.67)$ & $(-3.58)$ & $(1.65)$ \\
\hline \multirow[t]{2}{*}{ ENVORG } & 1.88 & $0.62 * *$ & 1.64 & $0.62 * *$ \\
\hline & $(1.33)$ & $(2.24)$ & $(1.21)$ & $(2.24)$ \\
\hline \multirow{2}{*}{ CONVEN } & -0.31 & - & -0.04 & - \\
\hline & $(-0.39)$ & & $(-0.05)$ & \\
\hline DROPOFF & $\begin{array}{l}1.58^{*} \\
(1.92)\end{array}$ & - & $\begin{array}{l}1.61 * * \\
(2.02)\end{array}$ & - \\
\hline \multirow[t]{2}{*}{ FORETHIC } & 0.75 & - & 1.15 & - \\
\hline & $(0.87)$ & & $(1.36)$ & \\
\hline \multirow[t]{2}{*}{ PREFCERT } & $8.56 * * *$ & - & $8.48^{* * *}$ & - \\
\hline & $(3.73)$ & & (3.83) & \\
\hline FORMONEY & - & $\begin{array}{c}0.30 * * \\
(1.99)\end{array}$ & - & $\begin{array}{c}0.32 * * \\
(2.09)\end{array}$ \\
\hline \multirow[t]{2}{*}{ CANTREDUCE } & - & 0.01 & - & 0.03 \\
\hline & & $(0.02)$ & & $(0.11)$ \\
\hline \multirow[t]{2}{*}{$\sigma$} & \multirow{2}{*}{\multicolumn{2}{|c|}{$\begin{array}{c}4.55^{* * *} \\
(4.64)\end{array}$}} & \multirow{2}{*}{\multicolumn{2}{|c|}{$\begin{array}{c}4.36 * * * \\
(4.79)\end{array}$}} \\
\hline & & & & \\
\hline \multirow[t]{2}{*}{$\rho$} & \multicolumn{2}{|c|}{$0.28 * * *$} & \multirow{2}{*}{\multicolumn{2}{|c|}{-}} \\
\hline & & & & \\
\hline Log-likelihood & & & & \\
\hline McFadden $\mathrm{R}^{2}$ & & & & \\
\hline LR test $\left(\chi^{2}\right)$ & & & & \\
\hline
\end{tabular}


Table 3. Estimated WTP for Various Sub-Groups

\begin{tabular}{|c|c|}
\hline Sub-sample & $\begin{array}{l}\text { Marginal Mean WTP } \\
\text { [lower, upper] }^{\mathrm{a}}\end{array}$ \\
\hline \multicolumn{2}{|l|}{ Marginal Mean WTP (entire sample) } \\
\hline A. REDUCE $=$ "yes" & $\begin{array}{c}4.04 \\
{[3.16,4.92]}\end{array}$ \\
\hline B. REDUCE = "no" & $\begin{array}{c}1.85 \\
{[1.41,2.29]}\end{array}$ \\
\hline C. Entire sample: Sum $=A+B$ & $\begin{array}{c}5.89 \\
{[4.91,6.88]}\end{array}$ \\
\hline \multicolumn{2}{|l|}{ Marginal Mean WTP (participants) } \\
\hline A. REDUCE = "yes" & $\begin{array}{c}5.17 \\
{[3.87,6.47]}\end{array}$ \\
\hline B. REDUCE = "no" & $\begin{array}{c}1.17 \\
{[0.67,1.67]}\end{array}$ \\
\hline C. All PART: Sum $=$ A + B & $\begin{array}{c}6.34 \\
{[4.94,7.74]}\end{array}$ \\
\hline \multicolumn{2}{|l|}{ Marginal Mean WTP (non-participants) } \\
\hline A. REDUCE = "yes" & $\begin{array}{c}2.18 \\
{[1.42,2.95]}\end{array}$ \\
\hline B. REDUCE = "no" & $\begin{array}{c}3.36 \\
{[2.46,4.26]}\end{array}$ \\
\hline C. All "no"NPART: Sum = A + B & $\begin{array}{c}5.54 \\
{[4.33,6.76]}\end{array}$ \\
\hline \multicolumn{2}{|l|}{ Marginal Mean WTP (non-targeted) } \\
\hline A. REDUCE $=$ "yes" & $\begin{array}{c}4.65 \\
{[3.51,5.79]}\end{array}$ \\
\hline B. REDUCE = "no" & $\begin{array}{c}1.15 \\
{[0.65,1.66]}\end{array}$ \\
\hline C. All NONTARG: Sum = A + B & $\begin{array}{c}5.81 \\
{[4.61,7.00]}\end{array}$ \\
\hline
\end{tabular}

${ }^{\text {a }} 95 \%$ confidence interval presented in brackets. Standard errors were calculated using the Delta Method Approximation (Greene, 2003). 
Table 4. Summary of WTP Comparisons for $\mathbf{H 1}$ and $\mathbf{H 3}$

\begin{tabular}{|c|c|}
\hline Hypothesis & $\begin{array}{l}\text { t-value } \\
\text { [result] }\end{array}$ \\
\hline \multicolumn{2}{|l|}{ H1: $W T P(R E D U C E=" y e s ") \neq W T P($ REDUCE $=" n o ")$} \\
\hline $\mathrm{WTP}_{\text {entire sample }}(\mathrm{REDUCE}=$ "yes" $)=\mathrm{WTP}_{\text {entire sample }}(\mathrm{REDUCE}=$ "no" $)$ & $\begin{array}{c}4.29 \\
\text { [REJECT] }\end{array}$ \\
\hline $\mathrm{WTP}_{\text {PART }}($ REDUCE $=$ "yes") = WTP PART $($ REDUCE $=$ "no") & $\begin{array}{c}5.60 \\
{[\text { REJECT] }}\end{array}$ \\
\hline $\mathrm{WTP}_{\text {NONPART }}($ REDUCE $=$ "yes" $)=\mathrm{WTP}_{\text {NONPART }}($ REDUCE $=$ "no" $)$ & $\begin{array}{c}1.96 \\
\text { [REJECT] }\end{array}$ \\
\hline $\mathrm{WTP}_{\text {NONTARG }}(\operatorname{REDUCE}=$ "yes" $)=\mathrm{WTP}_{\text {NONTARG }}(\operatorname{REDUCE}=$ "no") & $\begin{array}{c}5.47 \\
\text { [REJECT] }\end{array}$ \\
\hline \multicolumn{2}{|l|}{ H3: $W T P_{P A R T}=W T P_{N O N P A R T}$ and $W T P_{P A R T}=W T P_{N O N T A R G}$} \\
\hline $\mathrm{WTP}_{\mathrm{PART}}=\mathrm{WTP}_{\mathrm{NONPART}}$ & $\begin{array}{c}0.85 \\
\text { [CANNOT REJECT] }\end{array}$ \\
\hline $\mathrm{WTP}_{\text {PART }}($ REDUCE $=$ "yes" $)=\mathrm{WTP}_{\text {NONPART }}($ REDUCE $=$ "yes" $)$ & $\begin{array}{c}3.86 \\
\text { [REJECT] }\end{array}$ \\
\hline $\mathrm{WTP}_{\text {PART }}(\operatorname{REDUCE}="$ no" $)=\mathrm{WTP}_{\text {NONPART }}(\operatorname{REDUCE}=$ "no" $)$ & $\begin{array}{c}4.21 \\
\text { [REJECT] }\end{array}$ \\
\hline $\mathrm{WTP}_{\mathrm{PART}}=\mathrm{WTP}_{\mathrm{NONTARG}}$ & $\begin{array}{c}0.57 \\
\text { [CANNOT REJECT] }\end{array}$ \\
\hline $\mathrm{WTP}_{\text {PART }}($ REDUCE $=$ "yes" $)=\mathrm{WTP}_{\text {NONTARG }}($ REDUCE $=$ "yes" $)$ & $\begin{array}{c}0.58 \\
\text { [CANNOT REJECT] }\end{array}$ \\
\hline $\mathrm{WTP}_{\text {PART }}\left(\right.$ REDUCE $=$ "no") $=\mathrm{WTP}_{\text {NONTARG }}($ REDUCE $=$ "no") & $\begin{array}{c}0.06 \\
\text { [CANNOT REJECT] }\end{array}$ \\
\hline
\end{tabular}

